\title{
PLANEJAMENTO TERRITORIAL: SUAS IMPLICAÇÕES PARA A PROMOÇÃO DA SAÚDE E DA JUSTIÇA AMBIENTAL
}

\author{
Rafaela Rodrigues Pereira *
}

\section{RESUMO}

Há longa data o planejamento territorial urbano é foco de ações do poder público. O Estatuto das Cidades, que regulamenta os artigos da constituição federal que tratam da política urbana, tem sido considerado, por alguns estudiosos, um dos maiores avanços legais em termos de gestão e planejamento urbano no Brasil. Em sua seção I, O Estatuto das Cidades coloca como um dos instrumentos do planejamento territorial urbano, ao nível municipal, o plano diretor. Este, por sua vez, em termos legais, vem a ser uma ferramenta voltada para a gestão exclusiva de áreas urbanas, apesar de seu raio de atuação, em alguns municípios, abarcar áreas urbanas e não-urbanas - áreas rurais. Nesse ponto, reside o questionamento: Como esta ferramenta de gestão incorpora as demandas e conflitos ambientais inerentes a territórios tão particulares, não urbanos, mas intrinsecamente inseridos na configuração da rede urbana e que vêm sofrendo múltiplas e distintas pressões do meio, da lógica urbana? Assim sendo, no presente artigo, procurar-se-á trabalhar o tema acima, partindo de uma discussão mais ampla acerca de injustiça ambiental e desigualdades socioespaciais, focando, gradativamente, na questão das desigualdades espaciais intramunicipais, em municípios onde se verifica a existência de conflitos ambientais oriundos da interface rural-urbano. Neste contexto, o plano diretor é um instrumento de gestão que apresenta potencialidade para mediar o mencionado conflito.

\section{PALAVRAS CHAVE:}

Plano diretor, justiça ambiental, promoção da saúde, saúde ambiental e conflito rural-urbano.

\section{ABSTRACT}

The longstanding territorial urban planning is the focus of shares of public power. The Status of Cities, which regulates the articles of the constitution which deal with the federal urban policy, has been considered by some scholars, one of the biggest advances in terms of legal management and urban planning in Brazil. In its section I, The Status of cities poses as one of the instruments of territorial urban planning at the municipal level, the plan director. This, in turn, in legal terms, is to be a tool dedicated to the exclusive management of urban areas, in spite of its radius of action, in some municipalities, cover urban and non-urban - rural areas. At this point, is the question: Since this management tool incorporates the demands and environmental conflicts inherent in such private areas, not urban, but intrinsically inserted in the network configuration urban and who see suffering multiple and different pressures of the media, of the urban logic? Therefore, in this article, for it will work up to the subject, from a broader discussion about environmental injustice and inequality socio-spatial, focusing, gradually, on the issue of spatial inequalities within municipality in municipalities where verifies the existence of environmental conflicts from the rural-urban interface. In this context, the master plan is a management tool that has the potential to mediate the conflict mentioned.

\section{KEYWORDS:}

Master plan, environmental justice, health promotion, environmental health and rural-urban conflict. 


\section{Introdução}

Como consequência de um processo histórico de sucessão de modelos socioeconômicos pautados, em boa parte, pela supressão da maioria, verifica-se, hoje, a existência de uma desigualdade espacial sistêmica no território nacional. Nessa conjuntura, as populações mais vulneráveis, do ponto de vista político-financeiro, arcam com os custos socioambientais oriundos de um modelo de desenvolvimento que prima pela máxima produção em um curto período de tempo e a baixos custos financeiros, ignorando, em casos não raros, as inevitáveis consequências - de ordem negativa - geradas.

Estas desigualdades espaciais podem ser recortadas em diferentes escalas de análise, sejam elas ao nível inter-regional, interestadual ou mesmo inter e intramunicipal. No caso específico desta última, como caso emblemático, pode-se apontar a existências das zonas de sacrifício urbano, como é o caso das favelas.

A realidade acima delineada tem sido classificada por estudiosos, como um quadro de injustiça ambiental, cuja consequência é, entre outras, um risco à manutenção da saúde humana e do ambiente, ou seja, à manutenção da saúde ambiental.

Nesse contexto, o que se verifica é o delineamento de conflitos socioambientais, em que diferentes interesses confrontam-se na busca pelo direito e, por vezes, exclusividade, de uso de determinados espaços, configurando, dessa forma, disputas por territórios.

Não obstante, há longa data, o planejamento e a gestão territorial têm sido focos de atenção do poder público. Já na constituição de 1988, esses ideários se fazem presente, em seu Título VII, Capitulo II - Da política Urbana onde já há menção ao Plano Diretor. Mais recentemente, em 2001, com a regulamentação dos artigos 182 e 183 da Constituição de 1988, de maneira mais clara e delineada, o planejamento territorial, passa a ser tomado como caminho / alternativa de enfrentamento desses conflitos. Desta forma, tanto os planos diretores municipais, como as agendas 21 locais, apresentam potencial, através da participação das populações mais vulneráveis, para promoção da saúde e da justiça ambiental.

Assim sendo, no presente artigo, procurarse-á trabalhar o tema acima, partindo de uma discussão mais ampla acerca de injustiça ambiental e desigualdades socioespaciais, focando, gradativamente, na questão das desigualdades espaciais intramunicipais, em municípios onde se verifica a existência de conflitos ambientais oriundos da interface ruralurbano. Finalmente, pautando-se por esse foco, apontar-se-á como o planejamento territorial tem sido, ou pode vir a ser, uma ferramenta de promoção de justiça ambiental e saúde.

\section{Desigualdade Socioespacial Injustiça Ambiental}

O modelo de desenvolvimento políticoeconomico brasileiro, ao longo de sua formação histórica, tem se caracterizado pela produção de mecanismos estruturais de desigualdade e exclusão social, materializados pela distribuição, desigual e injusta, das riquezas e riscos por ele gerados, na qual as classes mais abastadas respondem pelos frutos e as mais vulneráveis pelos riscos.

Assim, com o intenso processo de industrialização e urbanização em curso nas últimas décadas, o que se verifica é a produção de espaços marginalizados, não apenas dos benefícios materiais e financeiros advindos da concepção produtiva vigente, mas também das políticas e ações do poder público que gerenciam os usos conferidos ao território nacional. O poder público, portanto, engendra em suas ações mecanismos de manutenção e perpetuação de desigualdades, por vezes, necessárias ao funcionamento do próprio sistema.

Esses fatores correlacionados apontam para o delineamento de um quadro que pode ser classificado como de injustiça ambiental que, de acordo com Leroy (2007), pode ser definida como 
(...) o mecanismo pelo qual sociedades desiguais, do ponto de vista econômico e social, destinam a maior carga dos danos ambientais do desenvolvimento às populações de baixa renda, aos grupos raciais discriminados, aos povos étnicos tradicionais, aos bairros operários, às populações marginalizadas e vulneráveis. (Leroy, 2007; p.2).

Não obstante, vale ressaltar que a injustiça ambiental não se restringe apenas à distribuição espacial desigual dos riscos e do acesso aos recursos do meio, mas também, à impossibilidade de exercício de outras práticas sociais, não ligadas à lógica produtiva ou à técnica vigente, mas aos modos de fazer socioculturais inerentes à apropriação simbólica do território por parte de cada grupo social. (Acselrad, 1999).

Fica claro, portanto, que os grupos sociais mais vulneráveis têm sua existência e reprodução comprometida tanto materialmente, quanto subjetivamente, apontando para o fato de que uma resposta a essa realidade não pode mais se restringir a fatores meramente técnicos e racionais. Sob essa ótica, Porto (2001) explica que

(...) nenhuma política que pretenda equacionar os graves problemas de saneamento, saúde e ambiente do país poderá ser efetiva sem que ocorram processos sociais de transformação que acabem com a produção estrutural endêmica de miséria, de desigualdades regionais e de exclusão social. (pág. 02).

A desigualdade espacial não se materializa, apenas, pela ausência ou presença de serviços básicos de infraestrutura, como rede coletora de esgoto e de abastecimento de água, serviço de recolhimento de lixo, acesso a serviços de saúde, asfaltamento de ruas etc., mas, principalmente, na lógica que rege a escolha dos lugares que contarão ou não com esses serviços, nos interesses que ditam para quais lugares serão destinados os resíduos de uma produção, o lixo de uma cidade, a construção de uma fábrica, o desmatamento / destruição de um ecossistema etc. Ainda na busca por um aprofundamento da questão, faz-se relevante perguntar, também, quais os quesitos que levam determinados lugares a serem convertido em áreas de preservação ambiental, pois, em um momento onde o mundo se questiona sobre a preservação do meio ambiente, muitos grupos tradicionais são expropriados de seus territórios para que uma visão de meio ambiente romantizada possa ser preservada.

Nesse processo, conflitos ambientais se delineiam, caracterizando-se tanto por uma disputa material quanto simbólica do território. Henri Acselrad (2004), a respeito desse fenômeno, irá definir tais conflitos como sendo

(...) aqueles envolvendo grupos sociais com modos diferenciados de apropriação do território, tendo origem quando pelo menos um dos grupos tem a continuidade das formas sociais de apropriação do meio que desenvolvem ameaçada por impactos indesejáveis - transmitidos pelo solo, água, ar ou sistemas vivos - decorrentes do exercício das práticas de outros grupos. (...) Esse conflito tem por arena unidades territoriais compartilhadas por um conjunto de atividades cujo "acordo simbólico" é rompido em função da denuncia dos efeitos indesejáveis da atividade de um dos agentes sobre as condições materiais do exercício das práticas de outros agentes. (Acselrad, 2004; p. 27).

Uma vez instaurada no território, a nova estrutura de poder, inerente a uma lógica de produção própria, marginaliza os agentes sociais não ligados a ela, tanto da nova lógica produtiva, como dos processos de tomada de decisão. Desse modo, para além de uma exclusão da apreensão material do meio, esses agentes, por não terem "voz" para se fazerem ouvir no espaço público, respondem, empiricamente, pelas cargas residuais dessa nova lógica produtiva e pelos riscos gerados. Ou seja, os menos favorecidos acabam ficando mais expostos às consequências, de ordem negativa, de uma técnica que não foi, e nem mesmo é, legítima para eles no plano simbólico. Uma técnica que foi pensada em outros espaços e simplesmente plotada em uma realidade a qual, em sua gênese, não pertencia, 
configurando, o que os estudiosos do tema denominam de "zonas de sacrifício", locais de forte risco ambiental e onde a "(...) desregulação ambiental favorece os interesses econômicos predatórios (...)". (Acselrad, 2004a; p. 14).

Nesse sentido, o território tanto é palco como objeto de anseio desta disputa material e simbólica. Portanto, em última instância, o que se tem é uma disputa por território, uma disputa pelo espaço enquanto instrumento de manutenção do exercício de poder. O território é, fundamentalmente, um espaço definido e delineado por, e a partir de, relações de poder. E este poder " $(\ldots)$ corresponde à habilidade humana de não apenas agir, mas de agir em uníssono, em comum acordo. O poder jamais é propriedade de um indivíduo; pertence ele a um grupo e existe apenas enquanto o grupo se mantiver unido". (Arendt, 1985:24 Apud Castro, 1995. p. 80).

O território, portanto, não é um espaço concreto em si, mais sim o espaço físico apropriado por um grupo social que, a partir de sua interação com os atributos daquele meio, desenvolvem uma identidade sociocultural, de modo que este grupo não pode ser mais compreendido sem seu território.

Nesse sentido, a constituição do território tanto é feita de relações de poder, quanto de relações de identidade, que implica a nomeação de elementos símbolos, representações deste espaço - signos, código de conduta etc. - sejam eles oficiais ou não, positivos ou negativos, revelando-se um território lugar.

A fragmentação do espaço, de maneira desigual e injusta, gerando um dégradé de espaços pobres, desprovidos de toda uma urbanidade, a áreas ricas, servidas de todos os equipamentos e infraestrutura urbana, promove não só uma exclusão social como uma exclusão territorial, alimentando e mantendo um quadro de injustiça ambiental.

\section{Desigualdade Espacial intramunicipal: A Interface Rural-Urbano.}

Como mencionado no tópico anterior, as desigualdades socioespaciais estão intimamente ligadas à lógica que gere a organização territorial. Esta, nas últimas décadas, por meio das ações do poder público, centrou-se na gestão territorial urbana. Entretanto, o acelerado e desordenado crescimento populacional urbano, associado ao modelo de urbanização brasileira, levou à criação de espaços centrais ricos e espaços periféricos pobres e paupérrimos, além de inúmeras "desapropriações" territoriais.

A ênfase em uma lógica urbanoindustrial tem exercido diferentes pressões em territórios particulares, não-urbanos, mas que estão intimamente relacionados à rede urbana, sendo fixos e de seus fluxos. Enquanto pressões presentes nessa dinâmica, pode-se apontar, entre outras, o ecoturismo, o acelerado processo de formação de micronúcleos urbanos e de áreas de proteção ambiental.

Cabe esclarecer que a relação campocidade aqui abordada não faz menção a uma contradição clássica, histórica, baseada na divisão do trabalho e na diferenciação bipolar de classes. Tratar-se-á aqui de uma relação reafeiçoada, centrada em uma nova hierarquia espacial, de centro e periferia, estabelecida por novas centralidades.

Os espaços rurais, dentro dessa nova lógica, que agregam um patrimônio ambiental paisagístico, o verde, são convertidos em espaços-mercadoria e, na lógica do turismo/ ecoturismo, passam a ser fator de geração de lucro. Estabelece-se, assim, novas relações entre as áreas e novos conteúdos para as relações sociais, tanto dentro dos territórios, como deste com o "mundo externo".

De maneira exemplificativa, tem-se o caso do Município de Nova Friburgo - RJ que, dos oitos distritos que compõe seu território, seis são rurais, ou seja, possuem maior parte da população em área rural, em detrimento da urbana. 
No caso particular deste município, o que se presencia é um gradual processo de urbanização de alguns de seus distritos rurais, advindo da emergência de uma funcionalidade turística conferida a eles.

O sétimo distrito deste município, o de São Pedro da Serra, pode ser tomado como exemplo desta conjuntura. Ele apresenta, acompanhando uma tradição da região Serrana Fluminense, significativo uso agrícola do solo. Entretanto, o manejo agrícola empregado é bastante impróprio, materializando-se em altas taxas de erosão, tendo, ainda, grande problemática com relação à pequena produção: os pequenos agricultores familiares tentam se adaptar ao modelo da agricultura moderna, mas se deparam com o problema da falta de recursos para investir na produção, carência de auxilio técnico por parte dos órgãos responsáveis, dificuldade de acesso a crédito e a prevalência de uma topografia acidentada e de várzeas estreitas e mal drenadas.

Diante de tal conjuntura, a atividade agrícola vem decaindo lucrativamente ao longo dos anos, em função, principalmente, da perda da base física de produção. Concomitantemente, há a constatação da veemência de um processo de recriação do espaço agrário, onde se verifica uma valorização das diferenças, das singularidades, que passa a caracterizá-lo como um espaço multifuncional e pluriativista: uma paisagem rural subordinada a uma lógica capitalista de consumo.

Não obstante, diante de um quadro de carência de políticas públicas voltadas para os interesses da pequena agricultura familiar e de uma valorização vertiginosa das terras promovidas pela especulação turística, o que se tem é um gradual abandono da atividade agrícola em favor da venda de propriedades e da busca por empregos no setor turístico, em atividades que exigem baixa qualificação, a baixas remunerações e sem vínculos empregatícios, configurando, portanto, uma situação de desapropriação territorial, visto que há um rompimento identitário do agricultor, da unidade familiar de produção, com o espaço físico socialmente construído.

Simultaneamente, todo esse processo, como já mencionado, dá-se diante de um quadro de carência de políticas públicas voltadas tanto para os interesses da pequena agricultura familiar, como da própria atividade turística, de modo que esta, sem contar com o apoio técnicofinanceiro dos órgãos competentes, vem crescendo desordenadamente.

Nessa conjuntura, enquanto o turismo cresce vertiginosamente, os investimentos em infraestrutura não o acompanharam com a mesma velocidade: não há tratamento de esgoto no distrito, as ruas de São Pedro da Serra são as mesmas de 25 anos atrás, que não foram modernizadas bem como novas ruas também não foram abertas, e não há um controle legal que trate de reger a atividade turística (área mínima dos loteamentos, cota de altura das construções...).

A ausência de assistência técnica apropriada na atividade agrícola contribui para a realimentação e manutenção de um ciclo vicioso ligado ao emprego de agrotóxicos que, sabidamente, são substâncias deletérias tanto para a saúde humana como para a saúde do meio. Seu emprego indiscriminado, sem orientação, ou pior, contando com a orientação de representantes de laboratórios, como é comum ocorrer, associados a outras práticas, como irrigação sem controle, não adoção de rotação de culturas, de pousio etc., corrobora com a necessidade de implementação de doses cada vez maiores de insumos agroquímicos, com vistas a compensar o desequilíbrio do sistema.

Consecutivamente, a prevalência de uma concepção preservacionista, ligada à questão ambiental, e a "venda" da paisagem verde pela atividade turística vem contribuindo sobremaneira para o gradual abandono da prática do pousio, visto que para o emprego deste faz-se necessário, posteriormente ao período de descanso, a limpeza do terreno com fogo, ponto neural no choque entre turismo e 
agricultura. A ausência dessa prática intensifica ainda mais o emprego de agrotóxicos.

A atividade turística, como o interesse em "manter" a paisagem verde a ser incorporada entre os atributos que justifiquem e legitimam sua prática e existência, tornou-se a maior fonte de denúncia das práticas de limpeza de terrenos com fogo. Essa postura é embasada pela existência do decreto $n^{\circ}$. 750, homologado em 1993. O referido decreto dispõe sobre o corte, a exploração e a supressão de vegetação primária ou nos estágios avançado e médio de regeneração de Mata Atlântica, e dá outras providências. A partir deste, como pressão por uma preservação ambiental, a atividade de agricultura familiar, com o emprego do manejo itinerante, praticado por comunidades tradicionais, passa a ser ameaçado.

Obviamente o decreto possui um papel importante no processo de tomada de consciência coletiva em relação à necessidade de recuperação e conservação da Mata Atlântica. Entretanto, resulta, em casos não raros, em práticas contrárias, em função, essencialmente, do fato de que sua formulação e implementação ignorou os contextos locais de produção e reprodução socioeconômica, forçando os agricultores a alterar sua sistemática de manejo, que já vinha de um processo de estrangulamento provocado pela implementação dos preceitos da revolução verde.

Em São Pedro da Serra, assim como em outras localidades onde se verifica a existência de comunidades tradicionais, a partir deste decreto, o pousio passou a ser feito em menor tempo, raramente ultrapassando três anos, a fim de evitar o impedimento, por parte dos órgãos fiscalizadores responsáveis, do corte das árvores posteriormente, em função do tamanho do peito já atingido por elas.

Completa o quadro da pressão advinda de uma visão de preservação ambiental, o fato de a área onde se encontra o distrito ter sido convertida em Área de Proteção Ambiental, a APA de Macaé de Cima, uma Unidade de Uso Sustentável, no ano de 2001, pelo Decreto no. 29.213. Entretanto, o processo de constituição desta não se deu de forma democrática, de modo que a população local sequer tomou conhecimento do fato no período, vindo a ser informada somente no ano de 2005, quando foi instituído, pelo Decreto $n^{\circ}$. 38.234, seu Conselho Gestor. Além disso, passados mais de cinco anos de sua instauração, a APA ainda continua sem Plano Diretor e/ou Manejo.

Não obstante, apesar do turismo colocarse como "defensor do verde", do meio ambiente, seu crescimento acelerado e desordenado, sem o devido acompanhamento de obras de infraestrutura, tem levado à contaminação dos recursos hídricos do distrito, em função do maior aporte de esgoto, visto que não há em São Pedro da Serra rede coletora de esgoto sanitário.

A presença de rede coletora de esgoto sanitário insere-se nos padrões de saneamento básico adequado. Sua ausência está diretamente relacionada a problemas de saúde humana, como, por exemplo, poliomielite, hepatite tipo A, giardíase, disenteria amebiana, diarréia por vírus, etc. A falta de saneamento, e particularmente a ausência de rede de esgoto, é o principal fator relacionado à morte de menores de cinco anos no Brasil, por diarreia.

Ao mesmo tempo, a demanda da crescente atividade turística por mão de obra, associada a fatores relacionados à expressividade do distrito em função do turismo, como maior número de ônibus ao longo do dia, presença de escola de nível fundamental e médio, posto de saúde, centro cultural, cinema etc., tem colocado o distrito como área de aporte migratório, tanto para a população dos distritos adjacentes, como para a população metropolitana que busca um modelo de vida distinto do grande centro.

Essa nova tendência vem, gradativamente, provocando um processo de inchaço no distrito, contribuindo para o agravamento das situações descritas acima, além de, por não ter como abranger a todos que chegam, levar a um pequeno processo de "favelização", que vulnerabiliza ainda mais uma parcela da população que já se encontra à margem desse processo.

Outro exemplo emblemático da interface rural-urbana, que cabe ser mencionado, se refere 
à população de caiçaras da Praia Grande da Cajaíba - Parati / RJ, onde se localiza a Reserva Ecológica de Jutuatinga. Nesta reserva reside há várias gerações uma comunidade caiçara.

Esta comunidade, especialmente entre 1950 e 1980, vivencia um conflito ambiental motivado pela chegada de grileiros e de uma forte especulação imobiliária, impulsionada pela atividade turística na área. No ano de 1990, esse problema torna-se ainda mais complexo com a criação de uma unidade de conservação de natureza non edificandi. De acordo com a classificação desta unidade não seria permitido implantar qualquer tipo de edificação na área. A necessidade de reclassificação gerou um conflito à parte. De acordo com Cavalieri (2004), com a criação da reserva a população não poderia mais plantar ou pescar, sob risco de serem punidos pela lei. Ainda, caso se lançassem em atividade no setor turístico, como alugar barcos para os turistas, vender produtos e afins, seriam descaracterizados como caiçaras e o processo de reclassificação da unidade ficaria comprometido, visto que não haveria uma comunidade tradicional a ser preservada.

Mais uma vez uma desterritorialização se desenha, na qual o caiçara, levado a um processo brusco de transformação, passa a vivenciar uma nova maneira de compreender sua realidade e, por reflexo, seu território e identidade.

Finalmente, cabe ressaltar que a ausência de um planejamento territorial que contemple a interface campo e cidade, procurando se aprofundar nos processos de desigualdade socioespacial inerentes a essa inter-relação, influencia, igualmente, no processo de desigualdade espacial dos padrões de saúde humana e ambiental.

\section{Planejamento Territorial como Ferramenta de Promoção de Saúde e Justiça Ambiental}

Como já mencionado, há longa data o planejamento territorial urbano é foco de ações do poder público. O Estatuto das Cidades, que regulamenta os artigos da constituição federal que tratam da política urbana, tem sido considerado por alguns estudiosos um dos maiores avanços legais em termos de gestão e planejamento urbano no Brasil.

Em sua seção I, O Estatuto das Cidades coloca como um dos instrumentos do planejamento territorial urbano, ao nível municipal, o plano diretor. Este, por sua vez, em termos legais, vem a ser uma ferramenta voltada para a gestão exclusiva de áreas urbanas, apesar de seu raio de atuação, em alguns municípios, abarcar áreas urbanas e nãourbanas, áreas rurais. Nesse ponto, reside o questionamento: Como essa ferramenta incorpora as demandas e conflitos ambientais inerentes a territórios tão particulares, não urbanos, mas intrinsecamente inseridos na configuração da rede urbana e que vêm sofrendo múltiplas e distintas pressões do meio, da lógica urbana?

O plano diretor, tanto na constituição como no Estatuto das Cidades, é apontado como o documento que guarda os preceitos de ordenação territorial necessários ao pleno cumprimento da função social da propriedade urbana:

Art. 39. A propriedade urbana cumpre sua função social quando atende às exigências fundamentais de ordenação da cidade expressas no plano diretor, assegurando o atendimento das necessidades dos cidadãos quanto à qualidade de vida, à justiça social e ao desenvolvimento das atividades econômicas, respeitadas as diretrizes previstas no art. 2o desta Lei. (Brasil, 2001).

Tal meta, ainda de acordo com o mesmo documento, somente pode ser alcançada através do emprego de um caráter participativo durante todo seu processo de elaboração, fiscalização e implementação. Para isso, os poderes Legislativo e Executivo, deverão assegurar a realização de audiências públicas e debates, que deverão contar com a participação da população e de associações representativas dos vários segmentos da comunidade, com a divulgação dos documentos e informações 
produzidos a partir destes fóruns de debates, além de garantir o acesso de qualquer interessado a esses mesmos documentos e informações.

É através do processo participativo e democrático que os grupos mais vulneráveis podem ter voz, colocar suas demandas e se tornarem atores ativos no processo. Esse é um dos principais fatores para o estabelecimento de uma situação de justiça ambiental, uma situação na qual

(...) um conjunto de princípios e práticas que asseguram que nenhum grupo social, seja ele étnico, racial, de classe ou gênero, "suporte uma parcela desproporcional das conseqüências ambientais negativas de operações econômicas, decisões de políticas e de programas federais, estaduais, locais, assim como da ausência ou omissão de tais políticas". (Porto, 2007.p.167)

Tal condição, a da adoção de um caráter participativo, é fundamental para a busca de um equilíbrio de força na disputa por territórios em conflitos ambientais, pois através dela há um empoderamento dos grupos mais vulneráveis, sejam eles inerentes a espaços urbanos ou rurais, pois estes, ao terem voz e espaço para se colocarem, não mais serão alijados dos processos de tomada de decisão.

Concomitantemente, servindo como instrumento de promoção de justiça ambiental, o plano diretor, enquanto ferramenta de gestão territorial urbana, também se coloca como um importante instrumento de promoção da saúde, tendo capacidade de agir nas diferentes dimensões que atuam sobre a saúde humana e do meio. Isso porque

o conceito de saúde implica o entendimento dos processos e condições que propiciam aos seres humanos, em seus vários níveis de existência e organização (pessoal, familiar e comunitário) atingir objetivos, realizações ou ciclos virtuosos de vida embutidos na cultura e nos valores das sociedades e seus vários grupos sociais. A saúde possui, portanto, além das biomédicas, dimensões éticas, sociais e culturais irredutíveis, sendo objeto de permanente negociação e eventuais conflitos dentro da sociedade, dependendo de como os valores e interesses se relacionam as estruturas de poder e distribuição de recursos existentes. (Porto, 2007. p.82).

Entendendo desta forma o conceito de saúde, sua promoção em contextos vulneráveis traduz-se na interação das questões éticas, sociais e culturais que influenciam na distribuição dos riscos, degradação dos sistemas ambientais e na fragmentação da dignidade humana e dos valores da sociedade.

Dessa forma, uma gestão territorial pautada nos preceitos acima delineados pode atuar diretamente nos determinantes espaciais da saúde, já que, como ressaltado anteriormente, saúde não se restringe à mera ausência de doenças, não faz referência apenas a fatores genéticos e biológicos humanos e aos ambientais mais imediatos, mas está intrinsecamente relacionado a determinantes sociais, econômicos, políticos e culturais, de maneira mais ampla.

Um planejamento territorial urbano assim delineado, ao promover a saúde ambiental, atua diretamente nas questões de saúde pública, contribuindo dessa forma para a construção de municípios saudáveis e para a manutenção dos sistemas de suporte a vida.

Nesse contexto, a elaboração e implementação do plano diretor pode contribuir para a criação de espaços de construção de políticas que atendam às necessidades da população através, principalmente, de agendas articuladas que contemplem estratégias de promoção da saúde como tema transversal no delineamento de um desenvolvimento saudável e sustentável.

O planejamento territorial deve ser tomado como pilar para a estruturação de mecanismos que possibilitem a superação do atual panorama de desigualdade socioespacial que influencia diretamente na qualidade de vida e na saúde humana e do meio. 


\section{Considerações Finais}

A superação das desigualdades socioespaciais é um desafio, não só hoje, mas desde longa data, que precisa ser superado. Quanto mais essa questão é ignorada e deixada em segundo plano pelas ações do poder público, mais grave torna-se o quadro.

As desigualdades e injustiças ambientais são engendradas no processo de reprodução do espaço, portanto, torna-se imprescindível a superação deste processo, que se traduz, no campo empírico, enquanto prática social.

O plano diretor é um instrumento de gestão, de cunho democrático, ainda bastante novo, mas que apresenta um significativo potencial para reverter processos de exclusão estruturais se conduzido de maneira participativa, ou seja, se promover, no âmbito das políticas públicas, a participação social, permitindo que as demandas de saúde ambiental, das populações mais vulneráveis, apresentadas por estas, sejam incorporadas.

Somente desta forma ele efetivamente pode conduzir, não apenas a propriedade urbana, mas a rede urbana, a cumprir sua função social, de modo que a reivindicação se traduza não pelo direito da moradia saudável em si, mas pelo direito à cidade, com todos a atributos que ela possa oferecer.

\section{Referências Bibliográficas}

ACSELRAD, H. Justiça Ambiental - novas articulações entre meio ambiente e democracia. In: Acselrad, H. Leroy, J. P. Novas Premissas da Sustentabilidade Democrática. FASE, RJ, 1999. $1-4 p$.

Conflitos Ambientais - a atualidade do objeto. Apresentação. In: Henri Acselrad. (Org.). Conflitos Ambientais no Brasil. Rio de Janeiro: Relume Dumará, 2004, v. , p. 7-11.

BRASIL. LEI No 10.257, DE 10 DE JULHO DE 2001. Regulamenta os arts. 182 e 183 da Constituição Federal, estabelece diretrizes gerais da política urbana e dá outras providências. Disponível em: <https:// www.planalto.gov.br/ccivil 03/Leis/LEIS 2001 LL10257. htm>. Acessado em: Set / 2007.

CASTRO, I. E., GOMES, P. C. C. e CORREA, R. L. Geografia: Conceito e temas. Rio de Janeiro: Bertrand Brasil, 1995.
CAVALIERI, Lucia. A comunidade caiçara no processo da reclassificação da Reserva Ecológica da Juatinga. 2004. Dissertação (Mestrado em Geografia - Geografia Humana) - Universidade de São Paulo.

LEROY, Jean. Conflitos ambientais na Amazônia brasileira. 6pp. Disponível em: < http://www.koinonia.org.br/tpdigital/ detalhes.asp?cod artigo $=79$ \&cod boletim $=4$ \&tipo =Artigo >. Acessado em Set / 2007.

PORTO, M.F de S. Saúde, Trabalho e Ambiente nos Territórios da Exclusão: Elementos para uma Promoção da Saúde Transformadora no Brasil. Bahia - Análise \& Dados, Salvador, v. 10, n. 1, p. 245-252, 2001.

Uma Ecologia Política dos Riscos: Princípios para integrarmos o local e o global na promoção da saúde e da justiça ambiental. Rio de Janeiro: Editora FIOCRUZ, 2007. 248pp.

Trabalho enviado em Junho de 2008

Trabalho aceito em Outubro de 2009 
